Printed in the United States of America. Available from National Technical Information Service

US Departmont of Commerce

5285 Port Royal Road

Price: Printed Copy \$4.00 Mictofiche \$2.25

Thin report was prepared as an acrount of wort sponsored bv the United siatem Government. Neither twe Uniled State nor the Injited States Ferey Rewrarch and Development Ad-

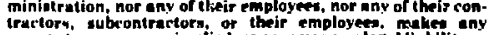

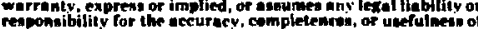
reapongibifity for the wecursey, completennes, of utefulmetn of repremente that its use would not infrinke privately owned

rizhls. 


\title{
DESIGN STUDIES OF HEAVY ION LINEAR ACCELERATORS CONSTRUCTED OF INDEPENDENTLY PHASED SPIRAL RESONATORS
}

\author{
by
}

\author{
Richard H. Stokes and Dale D. Armstrong
}

\begin{abstract}
Preliminary design studies are reported for two linear accelerators for heavy ions. One accelerater is a high-intensity machine which would operate with $100 \%$ duty factor and would produce tin ions with 6.1 MeV/A. Alternatively, it could be operated under pulsed conditions with $25 \%$ duty factor and would then accelerate uranium ions to $8.1 \mathrm{MeV} / \mathrm{A}$, tin ions to $10.5 \mathrm{MeV} / \mathrm{A}$, and all lighter ions to higher velocities. It would be injected with a positive multicharge ion source and a 4-MV single-ended dc generator. Also, design studies are reported for a small postaccelerator injected by a model FN tandem. Both accelerators use three-drift-tube spiral resonators operating at room temperature. Magnetic quadrupole singlets are placed between all resonators to provide radial focussing. Each resonator is independently phased according to the velocity of the ion to be acceleraced. The ability to adjust the phase of each resonator permits variations in final energy and other bean properties with great flexibility.
\end{abstract}

\section{INTRODUCTION}

In recent vears, heavy ion physirs and the possible existence of superheavy elements have received increasing attention. ${ }^{1,2}$ The Bromley report ${ }^{3}$ identifies heavy-ion physics as an important frontier area and as a high-leverage situation where small increases in funding could result in large increases in scientific productivity. This has placed great emphasis on developing a new generation of heavy-ion accelerators that are capable of performing precise experimental investigations. Beginning in 1968, the Los Alamos Scientific Laboratory (LASL) has had a growing interest in an improved heavy-ion facility for investigating the superheavy region. In 1969 a proposal ${ }^{4}$ was written to add a separated-sector cyclotron to existing tandem accelerator facilities. In 1971 a new approach was initiated to apply linear accelerator techniques to produce heavy-ion beams of suitably high energy. As a result of this, preliminary design work was done on an intermediate-size accelerator facility. Subsequently, a design was also developed for a tandem-injected postaccelerator. This report outlines the basic design characteristics and the expected performance of these two linear accelerators. Reports have been written that present results in several major areas, and other reports are now in preparation. We shall at tempt to present an overview of the properties of this form of linear accelerator with particular emphasis placed on subjects not covered elsewhere.

The los Alamos interest in a heavy-ion facility has been dominated by the basic nuclear physics investigations made possible by heavy-ion beams. especially by the predicted existence of superheavy elements, For such investigations the heavy ions must have energies that exceed the Coulomb harrier of the taryet nucleus. For certain types of experimen. ial work, the beam must have specific characteristics not now generally available. The

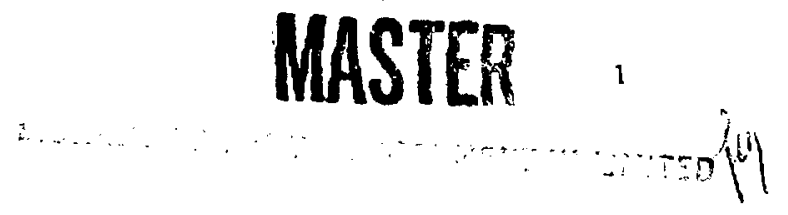


final energy should be capable of being varied in large or small steps over a wide range. Output beams with small energy spread, or microstructure pulses with small time spread, should be available according to the experimental technique in use. Especially for radiochemical investigations, high-intensity beams are necessary to increase the experimental sensitivity for important reaction products produced with very small cross sections. Also, the accelerator should produce beams of a wide variety of ion species to permit studies of the reaction mechanism of many projectile-target combinations. To permit efficiont collection of data from experimenis that use electronic detection, the macroscopic duty factor should be as large as possible.

To meet these requirements, a linear accelerator configuration was chosen. The simplicity and high efficiency of beam injection and extraction, together with the operating flexibility derived from independent phasing techniques, enable the above requirements to be met in a manner appropriate to the scope of the experimental program. In addition, a linear accelerator is easily extended to provide heavier ions or higher final energies should this become necessary in the future. Initially, we investigated the possibility of a superconducting linac, but decided that for the immediate future an accelerator operating at room temperature had the highast assurance of successful and reliable operation.

\section{ACCELERATING STRUCTURES}

In 1971 , we began to investigate the properties of the helix accelerating structure. ${ }^{5-7}$ Many $\lambda / 2$ electrical-length helix resonators were constructed and tested. Progress was made in optimizing the efficiency of the helix, and an accelerator was proposed $^{8}$ that consisted of an array of independently phased helix resonators operating at $50 \mathrm{MHz}$. Shortly after initial power tests were made with helix resonators, we cunstructed a new type of resonator ${ }^{9}$ with a drift tube supported on a spiral resonant structure. Although there was little guidance for the design, the first spiral resonator had a higher efficiency than our best resonator of the helix type. Further, initial power tests showed that the spiral resonator could be operated up to average axial fields $0.2 .6 \mathrm{MV} / \mathrm{m}$ with no feedback control. This indicated a much superior stability toward electromechanical osciliation.

The spiral resonator was immediately adopted as the basis for our accelerator design and about 150 model resonators were built and tested during late
1973 and early $1974 .{ }^{10}$ Maximum bare shunt impedance values ranged between 40 and $75 \mathrm{M} \Omega / \mathrm{m}$ depending on frequency, drift-tube size, spiral design, and phase velocity. A theoretical and experimental study ${ }^{11}$ of the spiral resonator was made in cooperation with the California Institute of Technology. Power amplifier and feedback control systems were developed ${ }^{12}$ to make full-power resonator tests and to study the acceleration and bunching of alpha particles. ${ }^{10}$ Coupled spiral resonators containing two or three active drift tubes supported on spirals were developed and tested at full power. ${ }^{10}$ Figure 1 is a schematic drawing of a three-drift-tube resonator. Other studies described later showed that these coupled resonators allowed suitably flexible acceleration characteristics, and the three-drift-tube resonator was adopted as the basic element for both the intermediate size accelerator and the postaccelerator. The three-drifttube resonator is described in Ref. 10 and in Appendix A. Measurements of shunt impedance were made over a range of frequencies and phase velocities, and on this basis a frequency of $100 \mathrm{MHz}$ was chosen for the intermediate size accelerator, and a frequency of $201.25 \mathrm{MHz}$ was tentatively chosen for the postaccelerator. Spiral resonators with a single drift tube were found to be convenient to use in bunching the beam before injection into the linac, and also for use in a debuncher to reduce the energy spread of the output beam. A more detailed description of these applications is included in the following sections.

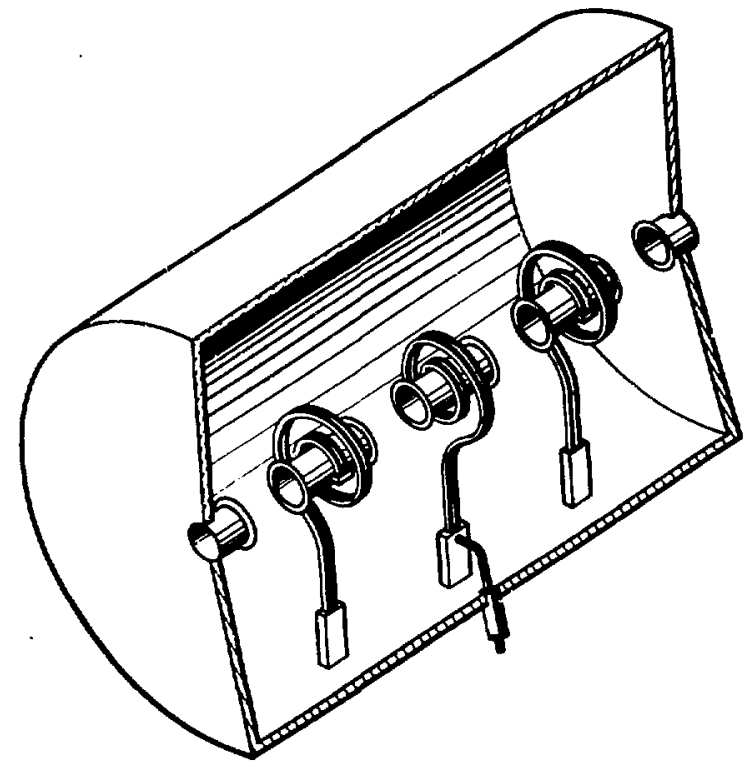

Fig. 1.

Three-drift-tube spiral resonator. 


\section{PRELIMINARY DESIGN OF AN INTERMEDIATE SIZE ACCELERATOR}

\section{A. Scope}

Theoretical results ${ }^{l}$ suggest that ions of intermediate mass such as ${ }^{48} \mathrm{Ca}$ or ${ }^{76} \mathrm{Ge}$ are expected to be optimum to use in the search for superheavy elements. Partly for this reason, we chose a facility of intermediate size. The facility could operate at $100 \%$; macroscopic duty factor and provide final energies above the heavy target Coulomb barrier for all ions through the middle of the nuclear chart. as shown in Fig. 2. Figure 2 also shows as a dashed line the out put energies available from pulsed operation at $25 \%$, duty factor. Figure 2 corresponds to full output intensity. and for experiments requiring smaller beam currents an increased energy would be available. A facility of this scope would have enormous capability for both nuclear and atomic physics research. Compared to a larger facility, it has the advantage that a single frequency can be used for the entire linac, and in addition, it could be constructed and become operational in a shorter time. After experimental programs develop and after the directions of heavy ion research becume more apparent, decisions regarding extensions of the facility could be made on that basis. Experience with the initial facility would provide guidance in choosing accelerator techniquess to be used in possible future extensions.

The basic elements of this design are the use of a dc injector containing a multiply charged ion source. the use of spiral resonator accelerating structures operating at room temperature, and the full use of

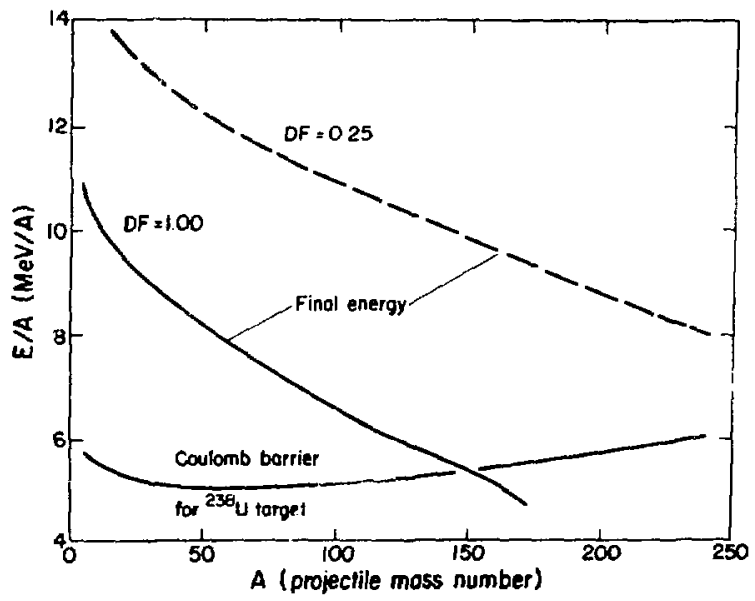

Fig. 2.

Ion energies for 25 and $100 \%$ duty factors compared to the Coulomb barrier of a ${ }^{238} U$ target. independent phasing of these structures to achieve a sufficiently broad velocity capability. We chose the acronym PHIl AC or DLAC for this Phased Heavy Ion Linear Acceleratror.

\section{B. Ion Source and Injector}

The requirement for relatively high-intensity beams to provide good sensitivity for low crosssection experiments led to the choice of a high charge state positive ion source. Using this type of source would require only one stripper to increase the ionic charge state. In addition, the published emittance characteristics of this type of source show that a good radial phase space match to the linac can be obtained through using a small single-ended dc injector. Ion source intensity data used to calculate output beam intensities are summarized in Sec. III.G.

The characteristics of the dc injector are imposed by both the ion source and the acceptance characteristics of the linac. Experimental work ${ }^{10}$ with spiral resonators operating at $100 \mathrm{MHz}$ showed that these structures could be used over a phase velocity range from 2.6 to $9.8^{\circ}$; of the velocity of light. To inject a ${ }^{124} \mathrm{Sn}$ ion with a charge of $9+$ at a velocity matching the lowest phase velocity requires a potential of about $4 \mathrm{MV}$. We adopted a 4-MV single-erided pressurized injector in a vertical configuration. This size would be small enough for rapid handling of the insulat ing gas to permit access to the ion source equipment $(1 / 2 \mathrm{~h}$ in, $1 / 2 \mathrm{~h}$ out $)$. The vertical configuration allows the high-voltage terminal to have the space and load capacity necessary to support several ion sources, a large generator, and terminal vacuum pumping equipment. Preliminary specifications ${ }^{13}$ were written and submitted to manufact urers of high-voltage equipment. Detailed replies from four companies showed that a satisfactory injector of this type could be purchased.

After the vertical injector, the beam enters a nagnet that gives a $90^{\circ}$ deflection and directs the beam into the single-drift-tube resonator used as the final buncher. The magnet selects a single ionic charge state, and also can be used with position detecting slits to provide a signal for feedback regulation of the injector potential.

\section{Design of Fesonator Phase Velocity Profile}

Most linear ion accelerators have been designed for a specific and inflexible operating condition. Both proton and heavy-ion linacs usually have been 
optimized for a fixed program of ion velocity vs position along the machine. Available sources of multiply charged heavy ions decrease in intensity with increasing charge state $q$. Wit:- increasing mass number $A$, the available charge $: \therefore$ mass ratio $\mathrm{q} / \mathrm{A}$ decreasf's for a specified output intensity, and to maintain adequate intensity, smailer $\mathrm{q} / \mathrm{A}$ ratios must be chosen for heavier ions. The velocity of ions from a fixed potential injector varies by almost a factor of two going from ${ }^{18} \mathrm{O}(5+)$ to ${ }^{124} \mathrm{Sn}(9+)$. To accelerate such a variety of ion beams, we used an array of independently phaser short resonators. Each resonator is operated with a radio-frequency phase chosen according to the velocity of the ion to be accelerated. In a previous report, ${ }^{8}$ we described the characteristics of short resonators that have an / $=\lambda$ sine wave axial electric field distribution. Such short resonators operating at fixed phase already have a rather broad capability for accelerating ions with different velocities. However, if $\gamma=\lambda$ resonators have their phase at the time of particle entry adjusted according to the ion velocity, then the velocity band over which they can accelerate efficiently is doubled. Several other attractive properties that accrue from using independent phasing include (1) a direct method to vary the energy of the output beam, (2) the possibility to control the ion beam dynamics through programming the synchronous phase, and (3) the use of a modular construction that would increase overall reliability.

Our experiments ${ }^{10}$ have shown that for a specified phase valocity range, the spiral resonator has a higher average shunt impedance if operated at a frequency higher than the helix resonator. At higher frequencies the length of a single-drift-tubis spiral resonator becomes less, and for a specified energy gain and electric field, a greater number of resonators would be needed. Because each resonator would be ?owered by a separate independently phased radio-tzequency system, there is an economic advantage to reduce the number of resonators as far as possible, consistent with the recuired velocity flexibility. This comes about particularly from the added cost of control systems required for each radiofrequency power and resonator combination. For this reason we have studied one-, two-, and threedrift tubes in a single container, with each drift tube supported on a separate spiral structure. In the twoand three-drift-tube configurations, the inner gaps between active drift tubes have twice the radiofrequency potential difference of the two end gaps. For example, see Fig. 3 which shows the measured axial electric field of a three-drift-tube resonator similar to Fig. 1. The points in Fig. 3 are determined by perturbing the resonator with a dielectric bead

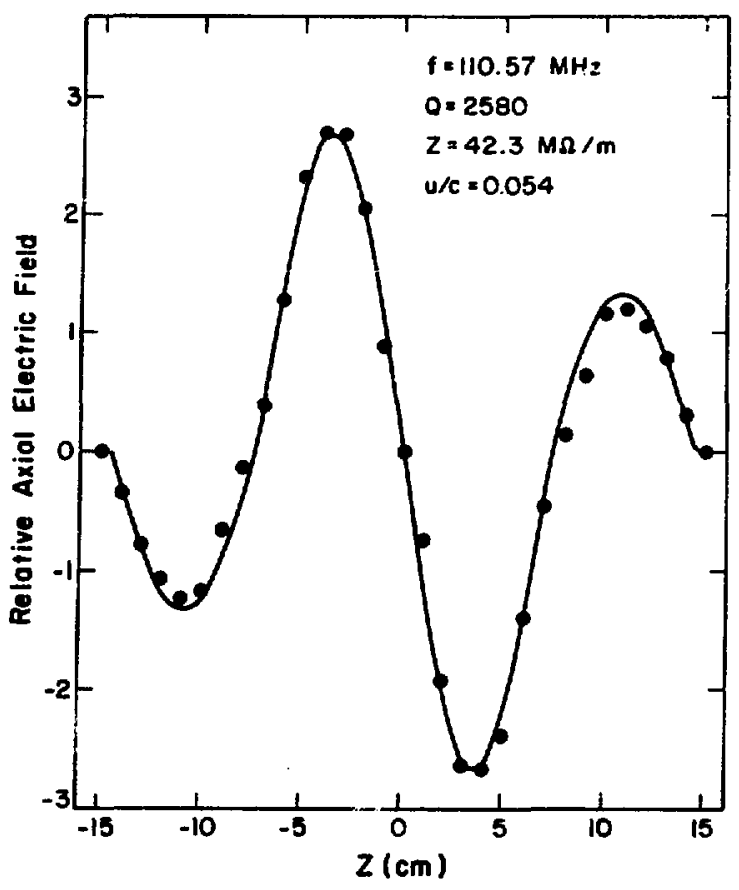

Fig. 3.

Axial electric field of a three-drift-tube resonator.

and by measuring the detuning phase shifts between an input antenna and a pickup probe. The curve is formed from sine wave segments of full and half amplitude, and corresponds to the electric field distribution $\mathrm{E}(\mathrm{z})$ used in the analysis given below.

The transit time factor $T$, for a resonator of axial length $h$, is defined as

$$
T=\frac{\int_{0}^{l} E(z, t) d z}{\int_{0}^{l}|E(z)| d z} \text {. }
$$

A particle of velocity $\mathrm{v}$ is assumed to travel through the resonator from $z=0$ to $z=1$, and $T$ closely approximates the ratio of the actual energy gain to the maximum gain possible if the field were not time varying. In Eq. (1) the denominator normalizes $\mathrm{T}$ so that it is unity if the electric field were applied at its maximum value whenever the particle is in the gap region, and then reverses sign appropriately as the particle passes between gaps. For the integral in the numerator we use

$$
E(z, t)=E(z) \cos (\omega t-\phi),
$$


where $\phi$ is the phase of the radio frequency at the time the particle enters the resonator. Maximum energy is gained for a synchronous particle (velocity equal to the resonator phase velocityl if the particle enters when all fields are zero so that it reaches a point half way through the first gap when the radiofrequency field is maximum. etc.

Respectively, for one-. two-, and three-drift-tube resonators we use

\section{$\ell=\lambda$}

$$
E_{1}(z)=A \sin \left(\frac{2 \pi}{l}\right) z, 0 \leq z \leq \ell,
$$

$\ell=3 / 2 \lambda$

$$
\begin{aligned}
E_{2}(z) & =A \sin \left(\frac{3 \pi}{\ell}\right) z, 0 \leq z \leq 2 \ell / 3 \\
& +A \sin \left(\frac{3 \pi}{l}\right) z, \ell / 3 \leq z \leq \ell,
\end{aligned}
$$

and

$$
\begin{aligned}
\frac{\ell=2 \lambda}{E_{3}(z)} & =A \sin \left(\frac{4 \pi}{2}\right) z, 0 \leq z \leq \ell \\
& +A \sin \left(\frac{4 \pi}{\ell}\right) z, l / 4 \leq z \leq 3 \ell / 4 .
\end{aligned}
$$

The phase velocity of the resonators is given by $u=f \lambda$, where $f$ is the operating frequency.

Integration of Eq. (1) with these three expressions: results in transit time factors that are functions of velocity and phase. It is convenient to use the variables $\gamma=u / v$, and $\alpha=\left(1-\gamma^{3}\right)^{-1}$. We obtain

$$
\begin{aligned}
T_{1}\left(\gamma_{,} \phi\right) & =\frac{\alpha}{4}[\cos \phi-\cos (\phi-2 \pi \gamma)], \\
T_{2}\left(\gamma_{2} \phi\right) & =\frac{\pi}{\theta}[\cos \phi-\cos (\phi-\pi \gamma) \\
& -\cos (\phi-2 \pi \gamma)+\cos (\phi-3 \pi r)] .
\end{aligned}
$$

and

$$
\begin{aligned}
& T_{3}(\gamma, \phi)=\frac{\alpha}{12}[\cos -\cos (\phi-4 \pi \gamma) \\
& +\cos (\phi-3 \pi \gamma)-\cos (\phi-4 \pi \gamma)] .
\end{aligned}
$$

If we take derivatives of these expressions with respect to $\phi$ and equate to zero, we obtain conditions on the radio-frequency phase at the time of particle ent ry into the resonator that maximizes the value of $T$. Call this value of the phase $\mu$. For the three distributions, we obtain

$$
\begin{aligned}
& \mu_{1}(\gamma)=\pi(\gamma-1 / 2), \\
& \mu_{2}(\gamma)=\pi\left(\frac{3 y}{2}-1\right), \quad \text { and } \\
& \mu_{3}(\gamma)=\pi(2 \gamma-3 / 2) .
\end{aligned}
$$

For the synchronous velocity, $\gamma=1, \mu=\pi / 2$ in all three cases. Corresponding to the requirement that $\phi=\mu(\gamma)$, the three transit time factors become

$$
\begin{aligned}
& T_{1}(\gamma)=\frac{\alpha}{2} \sin \pi \gamma, \\
& T_{2}(\gamma)=\frac{\alpha}{4}\left(\cos \frac{\pi}{2} \gamma-\cos \frac{3 \pi}{2} \gamma\right), \text { and } \\
& T_{3}(\gamma)=\frac{a}{6}(\sin \pi r-\sin 2 \pi r) .
\end{aligned}
$$

These have maximum values as follows.

$$
\begin{aligned}
& T_{1}(\gamma=0.8375)=0.8182, \\
& T_{2}(\gamma=0.9096)=0.8034, \\
& T_{3}(\gamma=0.9482)=0.7957,
\end{aligned}
$$

and all three expressions have the value $\mathrm{T}(\gamma=1)=$ $\pi / 4$. Figure 4 shows plois of Eqs. (12), (13), and (14) and the corresponding phase requirements Eqs. (9). 1101. and (11). All three curves for $\mathrm{T}(\gamma)$ are considerahly broader than the curves which result when E.gs. ((i). ( $(7)$, and ( $(8)$ are used with $\phi=\pi / 2$.

Phase stability is obtained in a manner completeIv analogous to that used in more conventional linac:. A synchronous phase $\mu_{0}$ is added to $\mu(\gamma)$. We have studied values of $\mu_{0}$ equal tc 20 and $30 \mathrm{deg}$. and have used 20 deg in the numerical calculations discussed helow. The value of $\mu_{0}$ need not be fixed. however. and considerable flexibility results in programming $\mu_{\text {o }}$ to vary along the acceleration cycle. For phase stable operation

$$
\mu=\mu_{0}+\mu(y), \quad 0<\mu_{0}<\pi
$$

and the energy gain for a particle of charge $q$ in a resonator of length $t=n \lambda$ is 


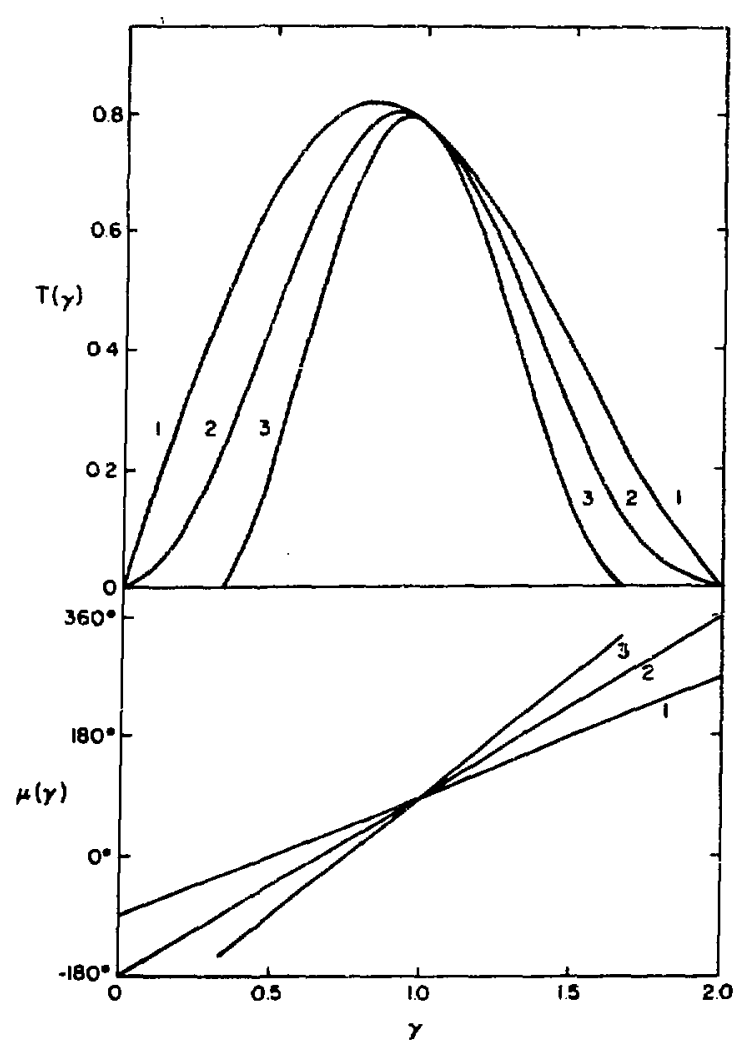

Fig. 4.

Transit time factors $T(\gamma)$ for one-, two-, and three-drift-iube resonators. $\gamma$ is the resonator phase velocity divided by the particle velocity. $\mu(\gamma)$ is resonator phase at the time of particle entry.

$$
\Delta E=q E_{0} T_{1}(\gamma) \& \cos \mu_{0}, \quad I=2 n-I,
$$

where $E_{0}$ is the absolute value of the axial electric field averaged over /. For the resonators we have studied, the sine wave approximation $t o F(z)$ introduces only very small differences in the energy gain compared to the use of a complete Fourier analysis of the measured $E(z)$ distributions. In the final design of an independently phased accelerator. a complete Fourier analysis of the measured electric fields in each type of resonator would he made. Then a generalization of the abrve calculation: would determine the phase setting for each resonator.

A computer program PROFIl. calculate the energy gain for an ion accelerated by a specific array of independently phased resonators.
Calculations were made for many arrangements using $T_{1}(\gamma), T_{2}(\gamma)$, and $T_{3}(\gamma)$. Resonators were assembled in groups having const ant phase velocity because the broad $T(\gamma)$ curves result in only a sniall loss of efficiency. Finally, a design based on $T: z(\gamma)$ was adopted and proved to have sufficient velocity breadth for the ions and energies desired. Appendix A summarizes the properties of the three-drift-tube resonator that corresponds to the choice of $T: a(\gamma)$. One foil stripper placed at an intermediate point was required to increase the ionic charge. After st ripping. the average charge state (which is approximately the maximum intensity component) was selected for further acceleration [see Appendix B, Eq. (B-7)]. The stripper position was determined by numerically solving an equation to determine the stripping energy that minimizes the length of the accelerator for a fixed final energy (see Appendix B). A ${ }^{124} \mathrm{Sn}$ ion was used to optimize the resonator arrangement. The initial charge state of the ions was chosen after examining published ion source data. ${ }^{14}$ All ions were injected into the linac with an initial velocity resulting from a 4-MV accelerating potential.

Figure 5 shows the results of optinizing the array for ${ }^{124} \mathrm{Sn}$ with an initial charge of $9+$. The resonators are assumed to operate at a $100-\mathrm{MHz}$ frequency and an average $1.5-\mathrm{MV} / \mathrm{m}$ axial electric field. Eight groups totaling 92 resonators were used with phase velocities from 2.58 to $9.81^{\circ}$ r of the velocity of light. $\mathrm{N}$ is the number of resonators in each of the eight groups. The phase velocity and $\mathrm{N}$ were chosen to

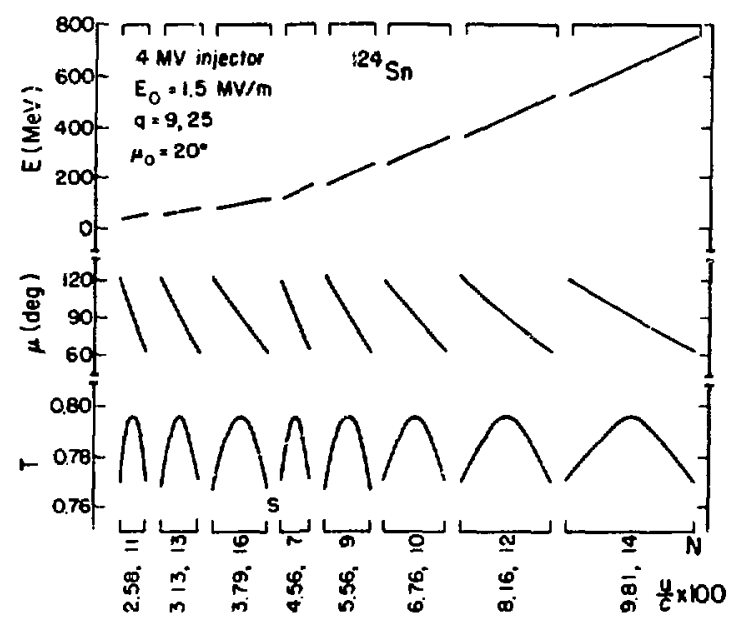

Fig. 5.

Acceleration cycle for ${ }^{124} S n$ ions. $N$ is number of identical resonators of phase velocity $u / c$ in rach of the eight groups. 
give an operating proint within each group having symmetrical and equal amplitude excursions over the transit time fact or $\mathrm{T}:(\gamma)$. These $\mathrm{T}$ excursions are shown at the bottom of Fig. 5. Each resonator is operated at a phase which is optimum for the velociI $y$ of the ion (modified by the synchronous phase). The phase variations $\mu=\mu_{11}+\mu:(\gamma)$ are plotted in the center of Fig. 5. At the top of the figure, line segments show the energy gain through each resonator group. A foil stripper is assumed to be placed after group 3 , and the +25 charge component is accepted for further acceleration in group 4 . At the bottom of the figure, broken line segments show the relative lengths of all the resonators in each velocity group. The choice of eight groups, with all resonators within a group being identical, results in an efticiency loss of only 1.4'; compared to making each resunator a different optimum phase velocity. The total effective potential of the resonators for ${ }^{124} \mathrm{Sn}$ is $34.14 \mathrm{MV}$, and the total length of the resonators alone is $30.85 \mathrm{~m}$. The total length of the prest ripper plus the poststripper, including quadrupoles, is 56 $\mathrm{m}$. Figure 6 shows the overall plan for the accelerator. The focussing system and the beam dunamics properties are discussed in Secs. D and E.

Finure 7 shows the effect of the same resonator array in accelerating ${ }^{76} \mathrm{Ge}$ ions. Each resonator phase was adjusted according to the velocity of the 7 Tige ion as it progressed through the accelerator. The final energy reached is about $4 "$ " less than if the resonator array had been optimized for tige. Similarly. Fig. 8 shows the acceleration cycle fir ${ }^{4} \mathrm{Ca}$ ions. The final energy is $12 \%$, less than if the linac were optimized for ${ }^{48} \mathrm{Ca}$. Tahle $\mathrm{I}$ lists fimal energies for various ions accelerated by the same resonator arrangement. Final energies with the single stripper in place are listed under heading E(1). For verv high intensity operation it is also possible to remove the stripper entirely and to use the initial charge state throughout. For this condi-

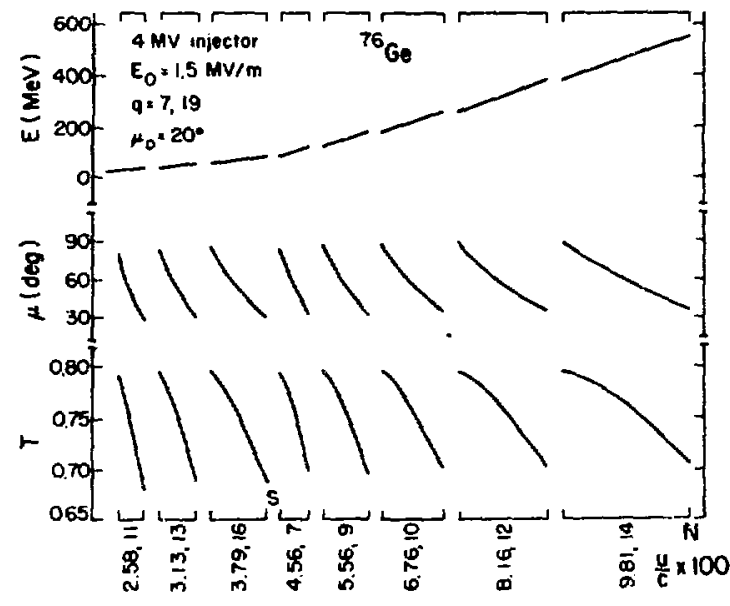

Fig. 7.

Acceleration cycle for ${ }^{76} \mathrm{Ge}$ ions.

tion, final energies are listed under heading $E(0)$. The lab Coulomb energy for a ${ }^{238} \mathrm{U}$ target is listed under the heading U-Barrier. The numbers in parens are the initial and stripped charge states of the accelerated ions. Appendix $\mathrm{C}$ describes the acceleration properties of this resonator array operating at $\mathrm{E}_{0,}=3.0 \mathrm{MV} / \mathrm{m}$.

Variation of the final energy would be accomplished through adjusting the phase of a suitable number of final resonators. If these final resonators operate with a synchronous phase of $\mu_{0}=\pi / 2$, they produce no energy gain, but still produce phase fincussing which preserves the time structure of the heam. Approximately every ther resonator can be turned off completely and the longitudinal focussing strength will be approximately equal to that obtained with all resonators operating at a synchronous phase of 20 or 30 deg. As discussed later. an increase in the energy resolution is available through a debuncher system. After acceleration, the ion beam

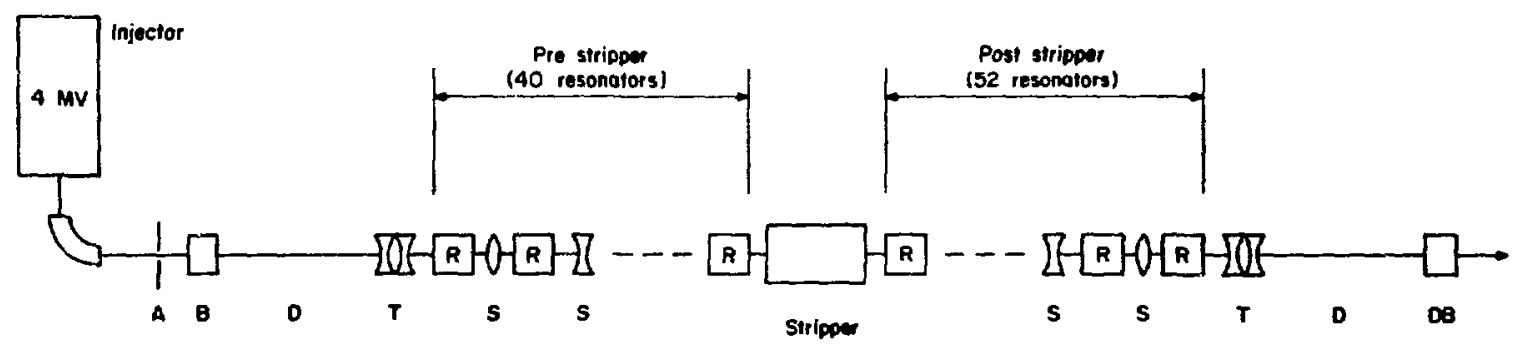

Fig. 6.

Schematic diagram of accelerator. The letters designate the following elements: A, aperture; $B$, buncher resonator; $D$, drift space; $D B$, debuncher resonator; $R$, spiral resonator; $S$, quadrupole singlet: $T$, quadrupole triplet. 


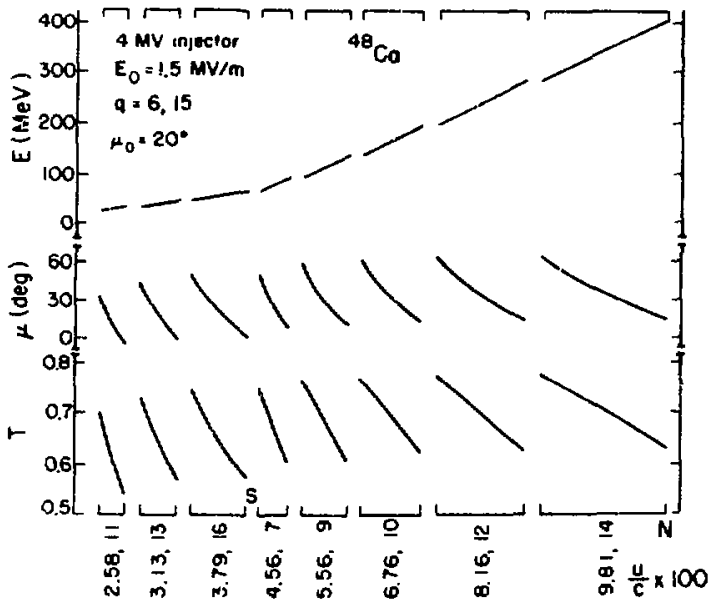

Fig. 8. Acceleration cycle for ${ }^{88} \mathrm{Ca}$ ions.

microstructure pulses are allowed to drift and debunch. and then a small energy correction is applied in a single resonator with one drilt tube. Typically. such an arrangement can reduce the heam energy spread by a factor of ten isee sec. III.E.).

In a room-temperature accelerator operating at 1010', duty factor, the radio-freouency power requirements are a dominating economic factor. Although other arrangements are possible. the present design with 92 independent ly phased resonat or: suggests use of 92 power amplifiers operat ing from a $l, w$-level reference phase line. Initial inquiries of commercial suppliers shows that there is no great

\section{TABLE I}

\section{FINAL ENERGIES (MeV)}

\begin{tabular}{|c|c|c|c|}
\hline Fon & U-Barrier & $\mathbf{E}(1)$ & $E(0)$ \\
\hline He $(2,2)$ & 24 & 45 & 45 \\
\hline${ }^{18} \mathrm{O}(5,7)$ & 91 & 175 & 147 \\
\hline${ }^{10} \mathrm{Ar}(\overline{5}, 13)$ & 206 & 346 & 178 \\
\hline${ }^{48} \mathrm{Ca}(6,15)$ & 231 & 406 & 214 \\
\hline${ }^{64} \mathrm{Ni}(7,18)$ & 331 & 506 & $24: 3$ \\
\hline Fife $(7,19)$ & 386 & 552 & 221 \\
\hline${ }^{86} \mathrm{Kr}(7.21)$ & 441 & 610 & 192 \\
\hline${ }^{101)} \mathrm{Mo}_{(8,2,3)}$ & 527 & 679 & 213 \\
\hline${ }^{124} \mathrm{Sn}(9,25)$ & 654 & 752 & 20.5 \\
\hline${ }^{1: 36} \mathrm{Xe}(9,26)$ & 721 & $77: 3$ & 177 \\
\hline${ }^{186} W(10,28)$ & 1074 & 517 & 132 \\
\hline
\end{tabular}

penalty in dividing the toral power erguipment intu smaller amplifiers compared to a few much larger radio-frequency power sources. In any case. the direct current supplies and the high-level input power handling equipment would be const ructed of a few large units. From shunt inipedance measurements of resonators with several phase velocities, estimates of the total radio-frequency power requirement were made lor $1(0)^{x}$, duty laclor operation. Individual resonators require $1(0)-\mathrm{MHz}$ power of approximately $7 \mathrm{~kW}$ for the lowest phase velocity (1) about $55 \mathrm{~kW}$ for the highest phase veloci1y. A total power of $2.2 \mathrm{MW}$ is estimated from present resonator measurements. Further improvements in resonator efficiency, coupled with an operating frequency of about $125 \mathrm{MH}$. could appreciably lower the required power.

With each resonator having its own radiofrequency power source, the failure of either a resonator or a power source would have minimal effect upon accelerator operation. If a fault develops. it is possible to deactivate the faulty resonator. and unless maximum out put energy is required operation can continue by rephasing all subsequent resonators. Also, the modular construction of the radis-frequency amplifiers and resonators, together with a standiby resonator and associated radiofrequency power module for each of the eight-phase velocity groups, would permit rapid replacement of a faulty unit.

The systems for control of resonator phase. amplitude, and frequency are described in Ref. 12. C'apability to adjust the phase of each resonator through a full range of 360 deg was one requirement. All conditions, such as operation at various energies. can be accomplished by having the resonators either operating at full amplitude or turned off. If pulsed operation is used, it would be necessary to add a second operating point as discussed in Appendix C. The feerlhark cont rol systems ${ }^{12}$ used for power tests of our spiral resonators had a phase stability of about 0.1 der and an amplitude stability of about $0.5 \%$.

\section{Design of Radial Focussing System}

'The design of the injection beam transport sistem, as well as the transport of the final acclerated heam. can be accomplished by standard methords. Because the beam dynamics of an indrpendently phased linac were unknown, our design offort was concentrated on obtaining appropriate radial and longitudinal characteristics in the main resonator array. In addition, studies were made of the stripper and debuncher systems, both of which 
had requirements closely related to this specific form of accelerator. Our experiments with spiral resonators show that shunt impedance values decrease with increasing drift-tube diameter. This factor. as well as additional mechanical rigidity requirements, made it desirable wo place the forcussing element between the resonators rather than inside the drift tubes. Our desire to study the radial transport properties of the linac for many configurations of the resonators and quadrupole focussing elements, and for a large number of ion species. rendered unateractive the usual approarch of I racing the trajestories of a large number of particles through the accelerator. Therefore. we adopted a modified version of one proposed by Junior and Deitinghoff. ${ }^{\text {is }}$ Our computer program LINACT is hasically a matrix method and is discussed in a separate repont. ${ }^{16}$ The customary transter matrices were generated to represent the quadrupole focussing elements and, with some approximations. matrices describing the defocussing effect of a resonator were generated. The validity of the approximations was tested by comparing the results of the matrix calculation to the results of a calculation (CPHILAC) that numerically solved the exact equations of motion. The iwo calculations agreed to within $l^{\prime} ;$. Because the ion velocities are a small fraction of the velocity of light. all sur calculations are nomrelativistic. 'The effect of the resonator magnetic fields is expected to be small and has been neslected.

Using LINACT we concluded that of the arrangements of resonators and focussing elements we studied, the one in which each resonator was followed by a magnetic quadrupole singlet was the most satisfactory. For one of the mutually orthogonal transverse directions the singlets were arranged in a $+-+-++-\ldots$ configuration. where + refers to a convergent lens and - refers to a divergent lens. Large radial acceptances for the linic' were obtained by operating the singlets in groups of four, all of which had the same magnitude of magnetic field gradient. An increase of 10 to 20 , in the radial acceptance resulted if the individual strengths were allowed to differ. This gain is more than offset by the economy achieved by reguiring only one power supply and cont rol for each group of four singlets. We found that a furt her economy could be effected by using singlet: of the same length for the prestripper section of the linac and a somewhat shorter singlet for ail the foc sising elements in the poststripper section. The minimum length for the singlets in both sections was dictated by our comstraint that the maximum magnetic field gradient required should not exceed $2 \mathrm{kG} / \mathrm{cm}$. a gradient available in commercial singlets of $5-(\mathrm{cm}$ aperture. $\mathrm{A}$ summary of our calculations for a representative selection of ion species is given in Table II.

The radial acceptances listed in Table II are idealized in that they were calculated assuming the relative phases and the amplitudes of the electric fields of the resonators could be set and maintained with irfinite precision. We also assumed that the effect of the stripping foil was negligible and that the particles entering the linac were monoenergetic and perfectly bunched. Our calculations show random variations of phase of less than $1 \mathrm{deg}$ and variations of electric field amplitude of less than 1', result in only few percent reductions of the radial acceptance. Buth degrees of stability were achieved using cont rol circuitry developed for tests of the spiral resonators. ${ }^{12}$ The multiple scattering in a 10. $\mu \mathrm{g} / \mathrm{cm}_{i}^{2}$ carbon stripper foil slightly increases the emittance of the prestripper beam. However. because the acceptance of the poststripper is larger than the prestripper emittance, the multiple scatiering has a negligible effect. To estimate the effect of

TABLE II

\section{RADIAL ACCEPTANCES AND QUADRUPOLE GRADIENTS}

\begin{tabular}{|c|c|c|}
\hline Ion & $\begin{array}{c}\text { Radial } \\
\text { Acceptance }^{\mathbf{a}} \\
(\pi \text { mrad-cm }) \\
\end{array}$ & $\begin{array}{c}\text { Maximum } \\
\text { Quadrupole } \\
\text { Gradient } \\
\text { (kG/cm) } \\
\end{array}$ \\
\hline${ }^{4} H \cdot(2,2)$ & 0.86 & 1.19 \\
\hline $160(5.7)$ & $1.4: 3$ & 1.37 \\
\hline${ }^{26} \mathrm{Mg}(3.9)$ & 1.06 & 1.76 \\
\hline${ }^{1}(1) \mathrm{Ar}(4.1: 3)$ & 1.72 & 1.34 \\
\hline${ }^{H 1} \mathrm{Ar}(\mathrm{i} .13)$ & 1.41 & 1.13 \\
\hline${ }^{H} \mathrm{C}$ a $(6,15)$ & 1.62 & 1.69 \\
\hline${ }^{(i+} \mathrm{Ni}(\mathrm{T}, 18)$ & 2.18 & 1.883 \\
\hline $76(\mathrm{re} \cdot(7.19)$ & 3.95 & 1.71 \\
\hline${ }^{86} \mathrm{Kr}(6,2(1)$ & 2.45 & 1.76 \\
\hline$\stackrel{1}{1 * 9} \mathrm{X} \times(9,26)$ & 4.56 & 1.56 \\
\hline
\end{tabular}

a Apertures $2 \mathrm{~cm}$ in diameter were used throughout the length of the linac.

b Magnetic quadrupole singlet leng hs of $20 \mathrm{~cm}$ were used in the prestripper portion of the linac. and singlet lengt hs of $12 \mathrm{~cm}$ were used in the poststripper portion. Each quadrupole was separated from adjacent resonators by a $6 . \mathrm{cm}$ space. 
the time and energy spread of the injected beam on the radial acceptance, we determined the bunching characteristics of a single drift-tube resonator with a drift space of $10 \mathrm{~m}$. This arrangement produces a 0.i)-ns particle bunch with $(\Delta \mathrm{E} / \mathrm{E}) \leq 0.0(0) 3$. The radial acceptance for the various particle species bunched in this manuer was greater than one-half of the values listed in Table II. The intensity estimates given in Sec. III.G have been adjusted to account for this decreased radial acceptance for a beam with realistic longitudinal spread. Finally, calculations show that variations of less than $0.1 \%$ in the quadrupole currents have a negligible effect upon the radiat focussing.

\section{E. Longitudinal Beam Properties}

'The computer program PHILAC?, which rep. resents an approximate but sufficiently accurate solution of the equations of motion, was used to study the longitudinal motion of the heam. This prouram determined the longitudinal acceptance by analyzing the phase-space trajectories for a number of particles differing at injection in time and/or energy. Fir all the ion species we studied, the longitudinal acceptance is adequat. to accommodate the $0.5-\mathrm{ns}$ and $(\triangle \mathrm{E} / \mathrm{E}) \leq 0.0(13$ beam bunch used in estimating the radial acceptance for a realistic injected beam. The errors in phase and amplitude that were acceptable for the radial motion were aiso acceptable in terms of their small effects on the longitudinal motion. 'The energy straggling in the stripper foil is small compared to the energy spread of the beam as it reaches the stripper foil, and we have consistently ignored its effect. The consequences of a radial variation of the sprace-average axial electric field was investigated. Mensurenents on test resonators indicate that this Field increases by less than $3^{\prime \prime}$; from its magnitude on axis to its magnitude at a position near the inside surface of the cirift tube. Such a variation causes only small perturbations in both the radial and longitudinal character of the beam.

We calculated the effect of using alternating phase focussing to eliminate some or all of the magnetic quadrupole singlets required to maintain stable raciial motion. The reduction in the longitudinal accept ance was so large that it would have negated the high-intensity aspect of our design. However, some programming of the magnitude, but not the sign of the synchronous phase, can be used to produce either a smaller time spread or a smaller energy spread in the beam as it leaves the linac without causing a large reduction of the longitudinal acceptance. This feature of an independent ly phased linac has not been explored fully, but is potentially attractive for use in more extreme modes of oppration.

For experiments requiring either good energy resolution or good time resolution, one or more resonators operated at low power levels can be placed between the linac and the experimental ayparatus to achieve the desired character of the beam at the target. Nominally these resonators would be operated with a synchronous phase of $\pi / 2$. For example, we have generated the longitudinal phase-space history of our typical beam bunch from injection, through the linac, followed by drift space, and through a debuncher resonator. The debuncher had the characteristics of a single drift-tube spiral resonator. Our calculations indicate that a drift space of $10 \mathrm{~m}$ between the linac and debuncher is $o p$ timum. With a resonator space-average electric field of $0.25 \mathrm{MV} / \mathrm{m}$, an energy resolution of a few parts in ten thousand is obtained. This is one-tenth the energy resolution of the beam as it leaves the linac. These results depend especially upon careful control of injection conditions. The input beam was assumed to be bunched as described previously. If the entire longitudinal phase-space acceptance of the linac is filled with injected particles, the output beam will have increased energy and time spread. Finaliy, calculations were made on systems to preserve the small time spread of the final beam for use in timeof-flight experiments. The calculations show that spiral resonators placed along the beam line between the accelerator and the experiment can result in heam bursts of a few tenths of a nanosecond duration at the target.

\section{F. Design of the Stripper System}

Conceptually, in our design the stripper system was treated as a separate entity with explicit functions to perform. It should accept from the prestripper portion of the linac various beams of ions with different, but well-defined, radial and longitudinal properties. It should provide a means of stripping the ions to a selectable charge state, and it should also provide a means of restoring the radial and longitudinal properties of the beam to conditions suitable for injection into the poststripper portion of the linac. $A$ system that met all these requirements was devised by using two magnetic quadrupole triplets and four 45 deg double focussing dipole magnets. Figure 9 shows the arrangement. 


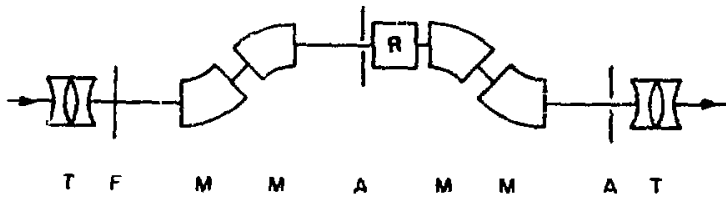

Fig. 9.

Sichematic diagram of stripper system. The Iotters designate the following elements; $A$, aperture; $F$, stripper foil; $M$, dipole magnet; $R$, ribunching resonator; $T$, quadrupole triplet.

One of the triplets was used to replace the last singlet in the prestripper linac and was separated from the linac by a short drift space. By allowing the gradients for each section of the triplet to be ad. justed individually, a waist was produced in the beam in both transverse directions at the position of the $10-\mu \mathrm{g} / \mathrm{cm}^{2}$ carhon stripper forl. Typically the waist was confined to an area less than $0.63 \mathrm{~cm}$ in diameter. The position of the stripper foil was close enough to the triplet to ensure that the angular divergence of the beam was large compared to the muitiple scattering angle.

Two of the dipole magnets were used to displace the stripped beam to a parallel position some distance from the axis of the linac. The edge focussing was adjusted to give equal focus lengths for bonh transverse directions, and the dipoles were positioned so the stripper foil was located at the object point. The charge separation slits were located at the $i m$ age point. Our calculations indicate that such a sivtem reduces the intensity of adjacent charge st ates of $\left.{ }^{124} \mathrm{Sn}(25)+\right)$ ions by more than a fact or of 10 . In making these estimates we have included the effect of the energy spread in the beam. A second cleanup of the stripped beam is accomplished by another set of two dipole magnets adjusted to have focal properties identical to those of the first sel. This second set imaged the beam passing throunh the charge separation slits onto a similar set of slits located on the linac beam axis. The second of the quadrupole triplets was operated in the same mode as the first, and it was used to prepare the stripped and analyzed beam for injection into the postst ripper linac. At the exit of the stripper system. the charue state impurity is less than 1", for the heaviest ions. The residual impurities have smaller or larger energy gain in the poststripper linne and can be highly discriminated against in the final switching magnet.

To compensate for the debunching of the heam as it drifts through the stripper system, a single resonator operated at a synchronous phase of $\pi / 2$ was placed between the first charge separation slits and the second set of dipole magnets. By proper selection of the amplitude of the resonator field. the longitudinal properties of the beam upon entering the st ripper region could be maint ained at the exit of the stripper system. The tot al length of the st rinper system between input and output resonators is 7.633 $\mathrm{m}$.

\section{G. Beam Intensity Calculations}

To characterize high-intensity operation of the proposed heavy ion linear accelerator, we have used ion source data published by the Berkeley Superhilac and Dubna laboratories. These laboratories use pulsed ion sources, which, for the Superhilac, are compatible with their accelerator duty cycle. For a description of high-intensity operation, we have used average values of their ion currents, and have not extrapolated the data to unity duty factor. Proper account was taken of the ionic charge state when computing particle intensities from the reported currents. The Superhilac reference gives $20 \pi$ and $31 \pi$ mrad-cm for the two radial components of the ion source emittance at a potential of $16 \mathrm{kV}$. We will simpiify slightly the calculations by assuming that both $x$ and $y$ components are equal and bu using an average value of $25 \pi$ when computing transmission efficiencies. The data for selected ions are listed in Table III.

Table IV lists final energies, transmission efficiencies, and final intensities for representative heavy ion beams. The final intensity is calculated by multiplyin: the product of the four efficiencies by the jon source intensities given in Table III.

These calculations show that this design has a large intensity advantage compared to proposals that use a tandem injector with one stripper in the tandem high-voltage terminal and a second stripper following the tandem. There is general agreement as 10 the low cross sections expected from many importan heavy ion nuclear reactions. Not all activities require high intensity, but it seems important to choose a design that will not rule out a large class of low cross-section experiments. In addition. this design is extensible to heavier ions and higher energies. However, tandem-injected arrangements mav not he extensible to higher intensities.

\section{H. Building Design}

An area $400 \mathrm{~m}$ southwest of the existing physics building. SM-40, is the proposed site for the facility. 
TABLE III

\section{ION SOURCE INTENSITIES}

\begin{tabular}{|c|c|c|c|c|}
\hline Ion & Reference & $\begin{array}{c}\text { Charge } \\
\text { State } \\
\end{array}$ & $\begin{array}{c}\text { Average } \\
\text { Current } \\
(\mu \mathrm{a}) \\
\end{array}$ & $\begin{array}{c}\text { Intensity } \\
\text { (ions/s) }\end{array}$ \\
\hline $\mathbf{M g}$ & a & 3 & 3180 & $66.3 \times 10^{14}$ \\
\hline Ar & b & 4 & 850 & $13.3 \times 10^{14}$ \\
\hline A & $c$ & 5 & 1000 & $12.5 \times 10^{14}$ \\
\hline $\mathrm{K}$ & c & 6 & 3200 & $33.3 \times 10^{14}$ \\
\hline & c & 9 & 500 & $3.9 \times 10^{14}$ \\
\hline
\end{tabular}

References

a B. F. Gavin, "Performance Characteristics of a Compact Self-Heated Cathode Source and Analyzer for the Berkeley 3-MV Superhilac Injector." Proc. of the Second Intl. Conf. on Ion Sources, Vienna. September 1972.

b A. S. Pasyuk, Yu. P. Tret'yakov, and S. K. Gorbacker, "Production of Multiply Charged Ions of Argon, Krypton, Xenon, and Tungsten by an Arc Source," Atomnaya Energiya 24, 21 (1968).

"Yu. P. Tret'yakov, A. S. Pasyuk, L. P. Kul'kina, and V. I. Kuznetsov, "Source of Multiply Charged Ions with Cathode Atomization of the Operating Substance," Atomnaya Energiya 28, 423 (1970).

TABLE IV

\section{FINAL ION ENERGIES AND INTENSITIES}

\begin{tabular}{|c|c|c|c|c|c|c|}
\hline \multirow[b]{2}{*}{$\operatorname{Ion}^{a}$} & \multirow{2}{*}{$\begin{array}{c}\text { Final } \\
\text { Energy }^{b} \\
(\mathbf{M e V})\end{array}$} & \multicolumn{4}{|c|}{ Efficiencies $^{c}$} & \multirow{2}{*}{$\begin{array}{c}\text { Final } \\
\text { Intensity } \\
\text { (ions/s) }\end{array}$} \\
\hline & & 11 & $\underline{2}$ & $\varepsilon: 3$ & 4 & \\
\hline${ }^{26} \mathrm{Mg}$ ( & 232 & 1.0 & 0.13 & 0.39 & 1.0 & $3.4 \times 10^{14}$ \\
\hline${ }^{40} \mathrm{Ar}(4,13)$ & 344 & 1.0 & 0.22 & 0.33 & 1.0 & $1.0 \times 10^{14}$ \\
\hline${ }^{10} \mathrm{Ar}(5$, & 346 & 1.0 & 0.18 & 0.33 & 1.0 & $0.8 \times 10^{14}$ \\
\hline${ }^{86} \mathrm{Kr}(6,2$ & 581 & 1.0 & 0.31 & 0.25 & 1.0 & $2.6 \times 10^{14}$ \\
\hline${ }^{129} \mathrm{Xe}(9,26)$ & 773 & 1.0 & 0.40 & 0.21 & 1.0 & $0.3 \times 10^{14}$ \\
\hline
\end{tabular}

- The initial and stripped charge states are given in parentheses. The ions that emerge from the source have additional electrons stripped off by passing through a thin foil placed between resonator groups 3 and 4 . After stripping. the maximum intensity charge state is accepted for further acceleration.

b The resonator array, frequency, and average axial electric field are the same as described in Sec. III.C.

$c$ The efficiency factors are defined as follows. $\epsilon_{1}$ - acceptance and transmission efficiency for the 4-MV injector that follows the ion source. The unjector has an acceptance of $57 \pi \mathrm{mrad}-\mathrm{cm}$ at 16 $k V$. Because this is much larger than the emit- tance of the ion source (25 $\pi)$, all values of $\epsilon_{1}$ are unity.

6.. - accept ance and transmission efficiency of the linac prestripper comprised of resonator velocity groups 1-3. After acceleration by the injector, the emittance of the beam is reduced to $1.58 \mathrm{mrad}$ $\mathrm{cm}$. The efficiency $t_{2}$ is the fraction of the beam accepted by the radial characteristics of the prestripper and also includes the losses introduced by the buncher that precedes the prestripper.

(:) - fraction of incident ions that emerge from the stripper with the charge state which has maximum intensity.

(1) - acceptance and transmission efficiency of the posist ripper linac. 
It would be necessary to extend Mercury Road across an earth fill for access to the area. The initial design of the building to house the accelerator is shown schematically in Fig. 10. A high bay area, about $15 \mathrm{~m}$ high would contain the vertical injector. The linac would extend along a corridor having concrete shielding on the side facing the office-laboratory area. Such shielding would be adequate for the $\mathrm{x}$-ray flux generated by electrons in the resonators. At the high-energy end of the accelerator, provisions were made for stacked concrete blocks along the fixed wall and around beam catchers. The large distance to other occupied buildings permitted a relaxation of the shielding requirements in directions other than the linac occupied areas. Initial Monte Carlo calculations made by using the geometry of the proposed building confirmed the feasibility of this arrangement. ${ }^{17}$

An experimental area was required to house major facilities as well as additional future beam lines. The major facilities were a Q3D magnetic spectrometer, a general-purpose scattering chamber, a time-offlight chamber, and an on-line isotope separator. All shielding in the experimental area consists of stacked concrete blocks to provide maximum operational flexibility and to permit building modifications.

The design of the office-laboratory area included a room for operating the accelerator. This same area would contain equipment necessary for collect ing experimental data. Rooms were provided for computer equipment to be used for accelerator operation and for experimental data collection. Also, laboratory space is provided for ion source equipment, vacuum

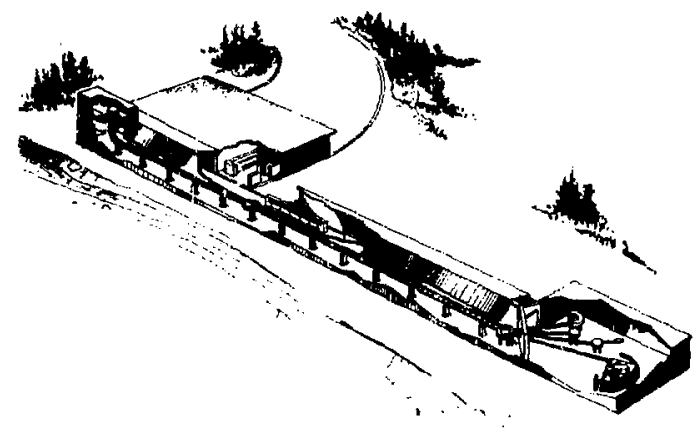

Fig. 10.

Schematic drawing of the facility. apparatus, electronics, radio-frequency equipment. and radiochemistry. A small machine shop. a stockroom, a drafting room, and office space for accelerator personnel were included. Faciiity users would have office space in nearby existing buildings. The overall length of the accelerator building is estimated to be $140 \mathrm{~m}$.

\section{DESIGN OF TANDEM-INJECTED POSTACCELERATOR}

\section{A. Scope}

The LASL tandem accelerator facility ${ }^{4}$ includes a vertical single-ended Van de Graaff machine and a High Voltage Engineeriag Model FN tandem. These two machines can be operated to perform nuclear physics measurements in separate experimental areas. Alternatively, they can be used for three-stage acceleration with the vertical machine injecting negative ions into the tandem. Foils are used for ion stripping in the high-voltage terminal of the tandem. For postaccelerator designing purposes, we assume that the vertical accelerator will operate at $6.5 \mathrm{MV}$ and that the tandem high-voltage terminal will operate at $8.5 \mathrm{MV}$. When the tandem is used to inject ions into the post accelerator, the ions would be stripped a second time in a foil placed at the tandem output. The numerical results presented in Table $V$ are based on using ions with the average charge state after each stripping process.

The ohjective was to add a small postaccelerator that would give a significant increase in the heavyion capability of the existing facility. It was hoped that the size would be compatible with housing the postaccelerator mostly in existing building space. Sumewhat arbitrarily ${ }^{34} \mathrm{~S}$ was chosen as the ion for which to optimize the design. This choice was a compromise that gave a new capability for a range of heavy ions and also gave additional energy to most lighter ions. The postaccelerator was optimized for injection by the tandem facility alone. The vertical accelerator, when available, could furnish three. slage injection which results in higher output energies, particularly for heavier ions. 
TABLE V

\section{ION ENERGIES FROM FN POSTACCELERATOR}

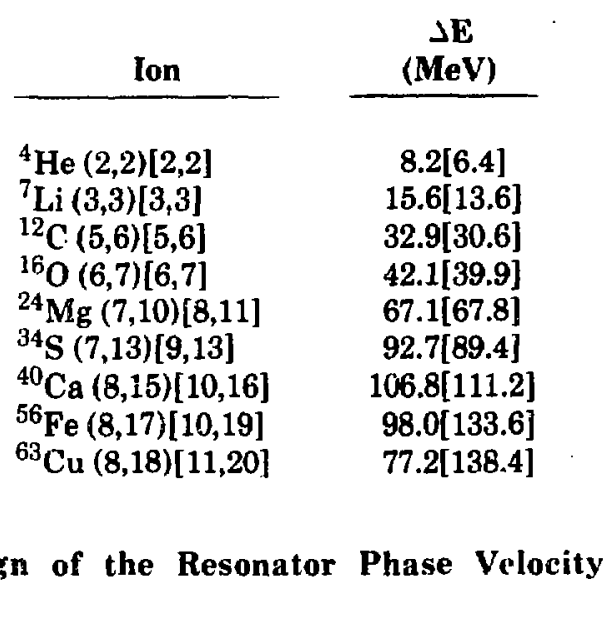

A negative ion of ${ }^{34} \mathrm{~S}$ reaches $8.5 \mathrm{MeV}$ at the tandem high-voltage terminal and strips to an average charge of $7+$. This ion is then accelerated to $68 \mathrm{MeV}$ at the tandem output and strips to a charge of $13+$. The code PROFILE was used to calculate the acceleration characteristics in a specified array of three-drift-tuhe resonators. It was efficient to use two phase velocity groups. The first group had 12 resonators with phase velocity $u / c=0.0682$. and the second group had 16 resonators with $\mathrm{u} / \mathrm{c}=0.0846$. The $201.25-\mathrm{MHz}$ frequency used at the LAMPF accelerator was chosen as the operating frequency and values of $\mathrm{E}_{01}=1.5 \mathrm{MV} / \mathrm{m}$ and $\mu_{11}=20 \mathrm{deg}$ were used as before. All the resonators were assumed 10 he independently phased. For tandem injection at 68 $\mathrm{MeV}$. the calculated output energy for ${ }^{34} S$ was 161 $\mathrm{MeV}$ corresponding to an energy gain of $9: 3 \mathrm{MeV}$ in the postaccelerator. The 28 resonators had a total length of $6.47 \mathrm{~m}$, not including quadrupoles. The overall length of the resonator quadrupole array is 13.2 $\mathrm{m}$. The effective potential for ${ }^{34} \mathrm{~S}$ was $7.13 \mathrm{MV}$. or approximately 20$)^{\prime}$ of the potential of the inter nediate size accelerator discussed in Sec. III. For an average shunt impedance of $50 \mathrm{MS} / \mathrm{m}$. the rotal power consumption is $291 \mathrm{~kW}$ for operation at $100 \%$, duty factor.

Table V summarizes the acceleration characteristics for a range of ion species. The charge states following stripping in the terminal and at the output of the tandem are listed in parentheses. The energy gain of the ions $\Delta E$ in the postaccelerator and their final energy $E_{f}$ are listed for tandem injection.

\begin{tabular}{c}
$\begin{array}{c}\mathbf{E}_{\boldsymbol{r}} \\
(\mathbf{M e V})\end{array}$ \\
\hline $33.7[38.4]$ \\
$49.6[54.1]$ \\
$83.9[88.1]$ \\
$101.6[105.9]$ \\
$135.1[150.8]$ \\
$160.7[180.9]$ \\
$183.3[211.2]$ \\
$174.5[233.6]$ \\
$153.7[246.9]$
\end{tabular}

\begin{tabular}{c}
$\begin{array}{c}\text { U-Barrier } \\
\text { (MeV) }\end{array}$ \\
\hline \\
24 \\
35 \\
69 \\
91 \\
136 \\
182 \\
229 \\
304 \\
343
\end{tabular}

'The values in brackets are for three-stage injection. U-barrier is the lab Coulomb barrier energy for the ions bombarding a ${ }^{238} \mathrm{U}$ target. The column labeled lon-Barrier gives the lab Coulomb barrier for the ions bombarding their own species. lons up through ${ }^{24} \mathrm{Mg}$ attain barrier energies for ${ }^{238} \mathrm{U}$. and ions up through ${ }^{63} \mathrm{Cu}$ are above the ion-ion barrier.

This particular resonator arrangement should be regarded only as a special example of what can be achieved. If a two-drift-lube resonator were used. the postaccelerator would have an increased efficienc. $v$ for both the lighter and heavier ions. For the same average electric field. frequency, and total potential. the number of resonators would be increased by a factor of about 1.5, that is, to a tot al of 42 resonators. If. however, the operating frequency were lowered to $100 \mathrm{MHz}$, the number of resonators would be reduced 10 one-half. An example of the use of two-drifttube resionators is given in Appendix D.

\section{Beam Transport and Properties}

('alculat ions using IINACT show that large radial acreptances can be obtained by using a configuration of alternating resonators and magnetic guadrupole singlets. The radial acceptances and magnetic field gradients we calculate for both tandem injection and for three-stage injection are listed in Table VI. In obtaining these accept ances we have used a 12-cm length for the quadrupole singlets and have assumed the useful area of the resonator drift tubes 10 he $2 \mathrm{~cm}$ in diameter. Each quadrupole was separated from adjacent resonators by a $6-\mathrm{cm}$ space. 
TABLE VI

\section{RADIAI, ACCEPTANCES AND QUADRUPOLE GRADIENTS FOR THE FN POSTACCELERATOR}

\begin{tabular}{lcc} 
lon $^{\mathbf{a}}$ & $\begin{array}{c}\text { Radial } \\
\text { Acceptance } \\
(\pi \text { mrad-cm) }\end{array}$ & $\begin{array}{c}\text { Maximum } \\
\text { Quadrupole } \\
\text { Gradient } \\
\text { (kG/cm) }\end{array}$ \\
\cline { 2 - 3 }${ }^{4} \mathrm{He}$ & $6.31(6.06)^{b}$ & $2.01(1.84)^{b}$ \\
${ }^{7} \mathrm{Li}$ & $6.39(5.75)$ & $2.09(1.81)$ \\
${ }^{12} \mathrm{C}$ & $6.24(6.19)$ & $1.77(1.84)$ \\
${ }^{16} \mathrm{O}$ & $6.46(6.37)$ & $1.88(1.92)$ \\
${ }^{24} \mathrm{Mg}$ & $6.75(6.59)$ & $1.72(1.86)$ \\
${ }^{34} \mathrm{~S}$ & $6.72(6.79)$ & $1.92(1.80)$ \\
${ }^{40} \mathrm{Ca}$ & $6.84(6.88)$ & $1.81(1.72)$ \\
${ }^{56} \mathrm{Fe}$ & $6.63(7.13)$ & $1.70(1.84)$ \\
${ }^{63} \mathrm{Cu}$ & $6.67(7.17)$ & $1.62(1.96)$
\end{tabular}

" The charge states and energy gains are given in Table V.

b The value in parentheses is lor three-stage injection; the ot her value is for tandem injection.

The acceptances for all the ion species are much larger than we would expect to be necessary to accommodate the high-quality beans that are knwwn to be produced by Van de Graaff accelerators. Although the second stripping that occurs in our design before injection into the postaccelerator will increase the radial emittance of the beam. S('(. III.I) shows that such effects are small. These observations suggest that a smaller diameter drift tube could be used in the postaccelerator resonators thereby increasing the shunt impedance and reducing the radio-frequency power consumption.
Calculations using PHILAC2 show that the injected bunch length should be $0.25 \mathrm{~ns}$ because our postaccelerator operates at $201.25 \mathrm{MHz}$. To achieve this bunch length, considerable care must be exercised in preparing the injected beam. Prebunchers located at the low-energy end of the tandem or in the head of the single-ended Van de Graaff would be used to produce nanosecond-long beam bursts at the buncher resonator. In our preliminary design. the stripper and charge state selection system immediately follow the tandem-accelerator analyzingmagnet slits. This system is followed by the buncher resonator. Nine meters of drift space between the buncher and the postaccelerator are allowed so the buncher introduces an energy spread of only $\Delta E / F \leq 0.003$. For estimating the degradation of the energy resolution of the beam by $t$ he postaccelerator. the longitudinal phase space histories for ${ }^{34} \mathrm{~S}(1: 3+)$ were generated. If a debuncher resonator is used 10 $m$ downstream from the postaccelerator. our calculations show that the energy resolution of the heam is only $20^{\prime}$; larger than that due to energy straggling in the stripper foil. This demonstrates that properly designed linacs are suitable for further acceleration of high-quality tandem beams with minimal degradation.

\section{ACKNOWLEDGMENTS}

Many individuals have assisted in the develop ment of this accelerator design. It is a pleasure to acknowledge the contributions of P. J. Bendt. C. R. Emigh, B. H. Erkkila. W. S. Hall, L. J. Laslett, A. J. Sierk, and T. A. Tombrello. The encouragement and guidance given bv H. T. Motz, R. B. Perkins, and R. $F$. Taschek were especially valuable.

\section{APPENDIX A}

\section{THREE-DRIFT-TUBE COUPLED RESONATORS}

The two accelerator designs discussed in Secs. III and $\mathrm{IV}$ are based on the resonator shown in Fig. 1. The resonator has three active drift tubes, each drilt tube supported on a separate spiral conductor. The resonator has three lowest mode resonant frequencies corresponding to the three degrees of freedom. The mode of interest has the lowest frequency when its efficiency is optimized by orienting adjacent spirals so that their directions of winding are opposite. This maximizes the inductive coupling for the mode in which adjacent drift tubes have opposite polarity and produces maximum shunt impedance. ${ }^{i(1)}$ Figure 3 shows the axial electric field distribution for a resonator of this type operating near $100 \mathrm{MHz}$. The experimental points are determined by perturbation measurements, and the curve 
is lormed of full- and half-amplitude sine wave segments. For the $\mathrm{E}_{3}(\mathrm{z})$ distribution given by $\mathrm{Eq}$. (5). the voltage difference between the center drift tube and the adjacent drift tube is

$$
\int_{\ell / 4}^{\ell / 2} E_{3}(z) d z=\frac{\ell}{\pi} A .
$$

For the whole resonator, the effective voltage is

$$
V=\frac{3 \ell}{\pi} \quad A=\ell E_{0},
$$

where $\mathbf{E}_{0}$ is the average axial electric field. Because $1=2 \lambda=2 \mathrm{u} / \mathrm{f}$, then

$$
v=\frac{2 u}{I} E_{0}
$$

and the maximum voltage across the inner two gaps is

$$
\frac{v}{3}=\frac{2 u}{3 f} E_{0} .
$$

For trequencies in the $100-\mathrm{MHz}$ range, the spiral resonator has the advantuge of small transverse dimensions. The resonator of Fig. 3 has a cylindrical wall with a $32.4-\mathrm{cm}$ inner diameter. For the resonators used in the accelerator design optimized for ${ }^{124}$ Sn (see Fig. 5), the resonator lengths for the smallest and the largest phase velocities are, respectively, 15.5 and $58.8 \mathrm{~cm}$. Radio-frequency power is brought into the resonator by attaching a conductor to the stem of the center spiral as shown in Fig. 1. Proper adjustment of the attachment point, together with a small series capacitor, allows the resonator $t o$ terminate a coaxial line in a resistive load of $\$ 0) \Omega$.
Resonators coupled through a coaxial line to a tetrode tinal-stage amplifier have been driven with powers up to $20 \mathrm{~kW}$. Single drift-tube resonators have been operated with average axial electric fields of $F_{\alpha}=2.6 \mathrm{MV} / \mathrm{m}$. Three-drift-tube resonators have been operated at our $1.5-\mathrm{MV} / \mathrm{m}$ design value. In the latter case the limitation was the source of radiofrequency power because there was no breakdown or other phenomena that prevented the attainment of higher values of $\mathbf{E}_{1}$.

The acceleration and bunching effects of spiral resonators have been studied ${ }^{10}$ by measuring the energy gain and time of arrival of alpha particles which have passed through the resonator. The alpha particles were detected with a silicon surface barrier detector connected to a multichannel pulse-height analyzer, and to a time-to-amplitude converter which compared the arrival time with the radiofrequency phase of the resonator. The absolute energy gain determined in these experiments was used to obtain independent values of shunt impedance. When these values were compared to the shunt impedance values from dielectric bead perturbation techniques, the agreement was within about 5 '

Finally, we emphasize the advantages of spiral resonators compared to helix resonators of $\lambda / 2$ electrical length. The spiral resonator can be designed to have a higher mechanical rigidity, and at the same time higher values of shunt impedance. Also, using drift tubes in the spiral resonator allows the elect ric field shape to be tailored independently of the radiotrequency resonant properties. With the helix it was possible to vary the field shape only within narrow limits. Also, the helix had the disadvantage of requiring cooling water at pressures in the 500- to 1000 psi range. Spiral resonators can be cooled adequately with normal pressure in the 50- to 100)-psi range.

\section{APPENDIX B}

\section{OPTIMIZATION OF STRIPPER POSITION}

By selecting an optimum stripping energy, it is possible to minimize the length of linear accelerator required to obtain a specified final energy. We will assume an accelerator with constant field gradient $F_{n}$, an injection energy $I$, an initial ionic charge $q_{1}$. and final energy $E_{f}$. The stripping energy is the sum of the injection energy, and the energy gained in length $L_{l}$ of the prestripper linac is

$$
E_{s}=I+E_{0} T q_{1} L_{1} \cos \mu_{0} .
$$

The energy gain in length $L_{2}$ of the poststripper is

$$
E_{f}-E_{s}=E_{0} T q_{2} L_{2} \cos \mu_{0},
$$

where $\mathrm{q}_{\mathrm{z}}$ is the charge state after stripping. The total length of linac is then 


$$
\begin{aligned}
& I=L_{1}+L_{2} \\
& =\frac{1}{E_{0} T \cos \mu_{0}}\left[\frac{E_{s}-I}{q_{I}}+\frac{E_{1}-E_{g}}{q_{2}}\right] \cdot(B-3)
\end{aligned}
$$

By taking the derivative with respect to $E_{s}$, we obtain

$$
\frac{d L}{d E_{s}}=\text { const. }\left[\frac{1}{q_{1}}+\frac{1}{q_{2}}\right]-\left(\frac{E_{1}-E_{s}}{q_{2}^{2}}\right) \frac{d q_{2}}{d E_{s}} .
$$

If we equate this to zero, we obtain

$$
\frac{q_{2}}{q_{2}}-\left(\frac{E_{f}-E_{s}}{q_{2}}\right) \frac{d q_{2}}{d E_{s}}-1=0 .
$$

Nikolaev and Dimitriev ${ }^{18}$ have derived a relation for the average charge state of an ion after passing through a solid foil. The formula agrees with experimental data over a wide range of ion velocity and charge number $\mathrm{Z}$. We will transform their expression by using the relation for the velocity of an ion of energy $\mathbf{E}(\mathrm{MeV})$ and mass number $\mathrm{A}$.

$$
v(\mathrm{~cm} / \mathrm{sec})=13.8913(\mathrm{E} / \mathrm{A})^{1 / 2} \times 10^{8} \cdot(\mathrm{B}-6)
$$

By substituting this into the relation of Ref. 18. we obtain for the average charge state after stripping

$$
q_{2}=z\left[1+\frac{0.10534 z^{0.75}}{(E / A)^{0.8333}}\right]^{-0.60}
$$

This relation has been used to obtain the stripped charge state when calculating the energy gain of ions with the code PROFILE. It is also used when solving Eq. (B-5) above. We calculate the derivative of $q$ : with respect to $E$, and obtain

$$
\frac{d q_{2}}{d E}=\frac{0.05267_{2}^{2.6667}}{A z^{0.9167}(E / A)^{1.8333}} .
$$

Using this expression in Eq. (B-5) allows one to solve numerically for a stripping energy which minimizes the accelerator length. For a final energy of $750 \mathrm{MeV}$. an initial charge $q_{1}=9, Z=50$, and $A=124$, the result ing energy is $E_{\mathrm{s}}=117 \mathrm{MeV}$. This is close to the energy of $113.4 \mathrm{MeV}$ which is reached by a ${ }^{124} \mathrm{Sn}$ $(9+1)$ ion after the third-phase velocity group of the resonator array of Fig. 5.

\section{APPENDIX C}

\section{PULSED OPERATION OF RESONATORS}

The machine described in Sec. III is a highintensity accelerator operating with $100 \%$; duty factor. Although unity duty factor is attractive for experiments that use electronic detection, it is not essential for some experiments in which higher energies may be more important. Because the accelerator design characteristically has a high intensity, the experimenter often would be willing to accept less than maximum intensity to achieve a higher final energy. We shall therefore discuss the operating characteristics that could be obtained in a puised mode of operation.

The resonator arrangement described in Sec. III. C was designed to operate with an average axial field of $\mathrm{F}_{*},=1.5 \mathrm{MV} / \mathrm{m}$. This is a very conservative field intensity compared to fields that have been reported. At Frankfurt, ${ }^{19}$ spiral resonators have been operated with maximum axial fields of $13.7 \mathrm{MV} / \mathrm{m}$. To demonstrate the properties of pulsed operation, we chose to use $\mathrm{E}_{01}=3.0 \mathrm{MV} / \mathrm{m}$, and to maintain the same average radio-frequency power consumption by reducing the duty factor to 0.25 . Energy gains were calculated for ions accelerated in the resonator array described in Sec. III.C. After the foil stripper. the ions had higher average charge states because of the greater energy gain in the prestripper accelerator. Table C-I lists the final energies $E(1)$ reached with the use of one foil stripper following the third resonator phase velocity group. The numbers in parentheses are the initial and stripped charge states used in the calculation. As before, for higher intensity operation, the stripper may be omitted. and for this condition the final energies are listed in the column labeled $E(0)$. The column labeled $I^{\circ}$. Barrier gives the approximate Coulomb barrier for these ions bombarding a ${ }^{238} U$ target. If the same transmission efficiencies are assumed, the average beam intensities with one foil stripper in use would be one-quarter of the values listed in Table IV. 
TABLE C-I

FINAL ENERGIES (MeV)

(Pulsed Operation, $\mathrm{E}_{\mathrm{o}}=\mathbf{3 . 0} \mathrm{MV} / \mathrm{m}$ )

\begin{tabular}{|c|c|c|c|}
\hline Ion & U-Barrier & $E(1)$ & $E(0)$ \\
\hline${ }^{4} \mathrm{He}(2,2)$ & 24 & 60 & 60 \\
\hline${ }^{18} \mathrm{O}(5,7)$ & 91 & 243 & 210 \\
\hline${ }^{40} \mathrm{Ar}(5,14)$ & 206 & 513 & 304 \\
\hline${ }^{48} \mathrm{Ca}(6,15)$ & 231 & 584 & 365 \\
\hline${ }^{64} \mathrm{Ni}(7,20)$ & 331 & 778 & 446 \\
\hline${ }^{76} \mathrm{Ge} \cdot(7,21)$ & 386 & 871 & 469 \\
\hline${ }^{8} \mathrm{Kr}(7,23)$ & 441 & 969 & 481 \\
\hline${ }^{100}$ Mo $(8,26)$ & 527 & 1111 & 551 \\
\hline $1.24 \mathrm{Sn}(9.29)$ & 654 & 1305 & 626 \\
\hline $1: 36 \mathrm{Xe}(0,30)$ & 721 & 1387 & 624 \\
\hline${ }^{186} W(10,35)$ & 1074 & 1733 & 640 \\
\hline $2: 38 \mathrm{U}(10,36)$ & 1444 & 1917 & $3: 38$ \\
\hline
\end{tabular}

With the use of one stripper. all ions com tort ably exceed the ${ }^{238} U$ Coulomb harrier. An examination of the details of the calculation shows the acroleration efficiency for $2: 18 \mathrm{U}$ ions to be very high. a result of the operating point remaining close to !he peak of the transit time factor curve for most of the accele ration cvele. This increased efficiency and the higher average charge states from the stripper produce greatly increased energies for the heavier ion species.

Similar calculations have been made for both the FN and MP postaccelerators. For example. the FN postaccelerator of Sec. IV with $\mathrm{E}_{w}=3.0 \mathrm{MV} / \mathrm{m}$ hals the following final energies: ${ }^{34} \mathrm{~S}, 236$ (249) $\mathrm{MeV}^{\prime}$ : and tiik $^{2}, 308$ (381) $\mathrm{MeV}$. The parenthetical values: result from three-stage injection. Similarly. for the MP postaccelerator of Appendix $D$ the final eneryiess are: ${ }^{4 R} \mathrm{Ca} .396 \mathrm{MeV}$; ${ }^{63} \mathrm{Cu} .499 \mathrm{MeV}$; and ${ }^{94} \mathrm{M}(1$. isios MoV. Thase energies from both postaccelerators exceed the Coulomb harrier energy of a $2: 38$ ( $i$ target. This possibility of extending the operation to a higher electric field condition again illustrates the inherent flexibility of an independently phased linear accelerator.

\section{APPENDIX D}

\section{MP TANDEM INJECTED POSTACCELERATOR}

A resonator arrangement has been designed for a postaccelerator injected by a Model MP tandem. The injection conditions and operating frequency were suggested by $H$. E. Gove of the Iniversily of Rochester. The tandem was assumed to operille at 12-MV terminal potential and foil strippingr was used in the terminal and at the tandem cutput. Following each stripper the average charge state of the ions was accepted for further acceleration. ${ }^{-1}{ }^{7} \mathrm{a}$ ions were used to optimize the resonatur phase velocities. To obtain greater efficiency for a broader spectrum of both lighter and heavier ions. the twodrift-tube resonator was used instead of the threedrift-tube type. Negative ${ }^{48} \mathrm{Ca}$ ions of $12-\mathrm{MV}$ energy strip to an average charge of $9+$ at the MP high. woltage terminal and reach a final energy of $120 \mathrm{M} \cdot \mathrm{V}$ at the tandem output. The ions are then stripped to charge $16+$ and injected into the resonators forming the postaccelerator. The resonators were assumed (1) operate at $100 \mathrm{MHz}$ with a synchronous phase $\mu_{11}=$ $20^{\circ}$, and with $\mathrm{E}_{10}=1.50 \mathrm{MV} / \mathrm{m}$.

Wit $h$ the above input conditions, an independently phased resonator array was assembled to accelerate ${ }^{48} \mathrm{Ca}$ ions to an energy above the Coulomb barrier for heavy targets. This resulted in two phase velocity groups: the first with 10 resonators having phasic velocity $u / c=0.0728$, and the second with 12 resunators with $u / c=0.0889$. The total lengt $h$ of the resonators alone was $8.07 \mathrm{~m}$, and for 4 ( $\mathrm{ca}$. the energy gain was $145 \mathrm{MeV}$ and the prostacceleralor out put energy was $265 \mathrm{MeV}$. The effective potential of the postaccelerator for ${ }^{4 R} \mathrm{Ca}$ was $9.07 \mathrm{MV}$. Table D.1 lists the eneryy gains $\triangle \mathrm{E}$ and the final energie: $F_{1}$ for 14 ion species. The ionic charge stat es following the two stripping stations are listed in parentheses. The column laheled ( -Barrier lists the approximate Coulomb barrier energies for thesc ions bumbarding a ${ }^{2}: 3 \mathrm{O} U$ target. Als" listed is the Coulomb barrier energy, Ion-Barrier, for those ions hombarding targets of their own nuclear species. All ions through iffFe exceed the ${ }^{2: t} 1 /$ barrier. and ions through ${ }^{79}$ Br exceed the ion-jon barrier.

The operating frequency of $10(1) \mathrm{MHz}$ is lower than that required to give minimum consumption of radio-frequency power. Based on experiments done at $1(k) \mathrm{MHz}$ with similar resonators, we estimate a lower limit for the shunt impedance to be $: 30 \mathrm{M} \Omega / \mathrm{m}$. For locie, duty factor operation. this gives an upper linit of $605 \mathrm{~kW}$ for the total radio-frequency power requirement. 
TABLE D-I

\section{ION ENERGIES FROM MP POSTACCEEERATOR}

\begin{tabular}{|c|c|c|c|c|}
\hline Ion & $\frac{1 \mathrm{E}}{(\mathrm{MeV})}$ & $\begin{array}{c}\mathbf{E}_{\mathbf{f}} \\
(\mathrm{MeV})\end{array}$ & $\begin{array}{c}\text { U-Barrier } \\
\text { (MeV) }\end{array}$ & $\begin{array}{c}\text { Ion- } \\
\text { Barrier } \\
\text { (MeV) }\end{array}$ \\
\hline${ }^{1} \mathrm{H}(1,1)$ & 3.1 & 27.1 & 13 & 1 \\
\hline${ }^{2} \mathrm{H}(1,1)$ & 5.2 & 29.2 & 12 & 1 \\
\hline${ }^{3} \mathrm{He}(2,2)$ & 10.2 & 46.2 & 24 & 2 \\
\hline${ }^{4} \mathrm{He}(2,2)$ & 12.2 & 48.2 & 24 & 2 \\
\hline${ }^{6} \mathrm{Li}(3,3)$ & 19.5 & 67.5 & 35 & 4 \\
\hline${ }^{12} \mathrm{C}(5.6)$ & 44.0 & 116.0 & 69 & 14 \\
\hline $160(6,7)$ & 54.6 & 138.6 & 91 & 23 \\
\hline${ }^{24} \mathrm{Mg}(7.11)$ & 92.1 & 188.1 & 136 & 47 \\
\hline $14 \mathrm{~S}(8,14)$ & 123.5 & 231.5 & 182 & 76 \\
\hline${ }^{48} \mathrm{Ca}(9,16)$ & 145.1 & 265.1 & 231 & 108 \\
\hline${ }^{i f} \mathrm{Fe}(10,20)$ & 181.1 & 313.1 & 304 & 175 \\
\hline${ }^{63} \mathrm{Cu}(10,21)$ & 188.5 & 320.5 & 343 & 210 \\
\hline${ }^{9} \mathrm{Br}(10.23)$ & 192.3 & 324.3 & 424 & 288 \\
\hline${ }^{96} \mathrm{M}_{1},(10.25)$ & 176.4 & 308.4 & 524 & 392 \\
\hline
\end{tabular}

\section{REFERENCES}

1. .J. R. Nix. "Predictions for Superheavy Nuclei," Phỵs. today 25. 30 (1972).

2. J. H. Hamilton and I. A. Sellin. "Heavy Ions-Looking Ahead." Phys. Today 26. 42 (1973).

3. "Physics in Perspective." National Academy of Sciences, Washington, D.C. (1972), Vol. 1, p. 438. Vol. IIA, p. 308 .

4. "Proposed Heavy Ion Facility at the Lus Alamos Scientific Laboratory." Edited by R. L. Henkel. H. T. Motz, R. H. Stokes, and R. F. Taschek. Los Alamos Scientific Laboratory report LA-42:38 (August 1969).

5. T. A. Tombrello, K. S. Jancaitis, P. J. Bendt. B. H. Erkkila, and R. H. Stokes, "Measurements and Calculations of FieId Distributions in Short Helical Resonators," Part. Accel. 4, 195 (1973).

6. P. J. Bendt. B. H. Erkkila, and R. H. Stokes. "Design and Measured Characteristics of MinimumLoss Low-Velocity Helix Resonators," IEEE Trans. Nucl. Sci. NS-20, 185 (1973).
7. P. J. Bendt, B. H. Erkkila, and R. H. Stokes, "Measurements on Half-Wavelength Helix Resonators," Nucl. Instrum. Methods 116. 555 (1974).

8. R. H. Stokes, "Proposed Accelerator for Heavy Ions," IEEE Trans. Nucl. Sci. NS-20, 159 (1973).

9. G. J. Dick and K. W. Shepard, "A Spiral Loaded Low- $K$ Accelerating Structure," Appl. Phys. Lett. 24. 40 (1974).

10. D. D. Armstrong. P. J. Bendt, B. H. Erkkila, J. S. Lunsford. P. J. Shiplev, R. H. Stokes, and J. Sutton. "Fxperimental Study of Spiral Resonators for Acceleration of Low Velocity Ions," To be published in Part. Accel.

II. P. J. Bendt, A. J. Sierk, and T. A. Tombrello, "Field Distributions in a Spiral Resonator." To be published in Nucl. Instrum. Methods.

12. I. S. Lunsford, J. P. Shipley, and J. Sutton, "l(k) $\mathrm{MH} z$ Power Amplifier Design and Control for a Heavy Ion Accelerator," Los Alamos Scientific laboratory report LA-5954 (April 1975).

13. R. H. Stokes and C. R. Emigh, "Preliminary Specifications for a 4 Megavolt High Voltage Injector System for a Heavy Ion Accelerator." InternaI document dated October 1973. 
14. J. R. J. Bennett, "High Charge State Heavy Ion Sources," IEEE Trans. Nucl. Sci. NS-18, 55 (1971).

15. P. H. Junior and H. Deitinghoff, "Low Magnetic Field Optimization of Focusing Devices in a Helix Linear Accelerator," J. Computat. Phys. 5, 1 (1970).

16. D. D. Armstrong and W. S. Hall. "Computer Programs for the Analysis of Heavy-Ion Linear Accelerator Beam Dynamics." LASL report in preparation.
17. R. Malenfant, Los Alamos Scientific Laboratory, private communication (December 1973).

18. V. S. Nikolaev and I. S. Dmitriev, "On the Equilibrium Charge Distribution in Heavy Element Ion Beams," Phys. Lett. 28A, 277 (1968).

19. H. Klein to R. H. Stokes, private communication (December 1974). 